\title{
Unjuk Kerja Kolektor Surya dengan Absorber Bentuk V yang Dilengkapi Honeycomb dengan Beberapa Aspek Rasio
}

\author{
Ekadewi A. Handoyo ${ }^{1}$, Niko Aris Sudiyanto², Prabowo ${ }^{3}$, Djatmiko Ichsani ${ }^{4}$ \\ ${ }^{1}$ Teknik Mesin, Institut Teknologi Sepuluh Nopember Surabaya \& Universitas Kristen Petra, Surabaya \\ 2,3,4Teknik Mesin-Institut Teknologi Sepuluh Nopember, Surabaya \\ Email: ekadewi@petra.ac.id
}

\begin{abstract}
ABSTRAK
Alat yang memanfaatkan radiasi matahari secara sederhana tetapi penting dan dapat menolong masyarakat di daerah tropis seperti Indonesia adalah kolektor surya. Kolektor surya dapat diaplikasikan sebagai pemanas udara untuk proses pengeringan hasil pertanian. Salah satu upaya untuk meningkatkan unjuk kerja kolektor adalah menggunakan plat absorber berbentuk $\mathrm{V}$ atau memasang honeycomb di atas plat absorber untuk mengurangi rugi panas. Pada paper ini dibahas penggabungan keduanya. Dari hasil pengujian didapat bahwa kolektor surya dengan plat absorber bentuk $\mathrm{V}$ yang dilengkapi honeycomb mempunyai unjuk kerja terbaik saat udara mengalir dalam saluran dengan kecepatan $0,5 \mathrm{~m} / \mathrm{s}$ dengan aspek rasio $\mathrm{H} / \mathrm{L}=$ 3/1. Unjuk kerja yang dimaksud adalah efisiensi kolektor dan kenaikan temperatur aliran udara melintasi kolektor.
\end{abstract}

Kata kunci: Kolektor surya, plat absorber V, honeycomb.

\begin{abstract}
A simple apparatus using solar radiation that is essential for people in tropical area like Indonesia is called solar collector. A solar collector can be applied to heat air which can be used to dry some crops or agricultural products. One of some effort to improve the solar collector performance is using a v-corrugated absorber plate or installing slats in a honeycomb shape over the absorber to reduce heat loss. This paper will describe the combination of both. From the research, it was found that a solar collector with v-corrugated absorber plate has its best performance when the velocity of air is $0.5 \mathrm{~m} / \mathrm{s}$ with aspect ratio $H / L=3 / 1$. The performance includes the collector efficiency and the increase temperature of air flowing through the collector.
\end{abstract}

Keywords: Solar collector, v-corrugated absorber plate, honeycomb slats.

\section{PENDAHULUAN}

Akhir-akhir ini banyak negara dan institusi yang mencanangkan tekad dan semangat untuk mengurangi pemakaian bahan bakar minyak agar polusi gas buang berkurang dan bumi menjadi lebih sehat. Hal ini mendorong peningkatan penggunaan sumber energi terbarukan. Salah satu sumber energi terbarukan yang melimpah di Indonesia yang terletak di daerah katulistiwa adalah energi matahari.

Energi radiasi yang dipancarkan matahari dapat ditangkap dalam suatu kolektor yang digunakan untuk memanaskan air atau udara. Pemanas air mempunyai kelebihan dalam hal air mempunyai kapasitas termal yang tinggi sehingga dapat menyimpan panas lebih lama daripada udara. Namun, udara lebih ringan dan lebih tidak bersifat korosif dibandingkan air. Udara juga dapat digunakan secara langsung untuk proses pengeringan yang membutuhkan temperatur rendah atau sedang, misalnya pengeringan hasil pertanian, ikan, dan lain-lain.

Problem terbesar yang dihadapi kolektor udara adalah rendahnya koefisien perpindahan panas konveksi antara permukaan plat absorber dengan udara yang mengalir di bawahnya. Hal ini mendorong banyak peneliti untuk mengupayakan kenaikan koefisien konveksi. Choudhury et al. [1] membandingkan kinerja kolektor surya dengan plat absorber yang berbentuk gelombang atau $\mathrm{V}$ dengan plat absorber yang datar. Hasil yang dipaparkan adalah bahwa plat absorber bentuk $\mathrm{V}$ memberikan efisiensi lebih tinggi dari yang datar. Metwally et al. [2] mengevaluasi unjuk kerja kolektor surya udara dengan beberapa bentuk saluran dan menemukan 
bahwa plat bentuk $\mathrm{V}$ memberikan kenaikan temperatur udara tertinggi saat udara mengalir di bawah plat tersebut. Selain itu, Metwally juga menemukan aspek rasio saluran (didesiripisikan sebagai perbandingan kedalaman saluran terhadap lebar satu gelombang) untuk kemiringan gelombang dengan sudut $30^{\circ}$ yang terbaik adalah 0,61 dibandingkan rasio lain yang diteliti, yaitu: 0,30 dan 0,92. Karim et al. [3] menemukan bahwa kolektor dengan plat absorber bentuk V lebih efisien $10-15 \%$ dibandingkan plat datar untuk single pass dan 5 $11 \%$ untuk double pass.

Selain koefisien konveksi antara absorber dengan udara yang rendah, masalah lain yang dihadapi kolektor udara adalah adanya kehilangan panas ke lingkungan. Upaya yang sering dilakukan adalah memasang 'penghalang' untuk memperkecil rugi-rugi kehilangan panas dari absorber ke kaca penutup dan ke lingkungan. Metwally et al. [2] mengevaluasi unjuk kerja kolektor matahari udara dengan penambahan penghalang berupa honeycomb/ slat pada beberapa rasio slat. Slat yang dipasang tidak menyentuh kaca penutup dan absorber. Hal ini dibuat untuk menghindari efek sirip yang dapat memperbesar kehilangan panas dari plat absorber ke kaca penutup. Ada dua rasio yang digunakan, yaitu: aspek rasio slat, $\mathrm{AR}_{\mathrm{s}}$, yang didesiripisikan sebagai ketinggian slat dibagi celah antar slat dan aspek rasio saluran, $\mathrm{AR}_{\mathrm{C}}$ yang didesiripisikan sebagai tinggi saluran yang bergelombang dibagi lebar gelombang. Kolektor dengan aspek rasio slat, $\mathrm{AR}_{\mathrm{S}}=2,0$ dan aspek rasio saluran, $\mathrm{AR}_{\mathrm{C}}=0,61$ menghasilkan peningkatan efisiensi kolektor 34\% lebih besar daripada kolektor tanpa slat. Suehrcke et al. [4] membandingkan koefisien perpindahan panas konveksi beberapa macam 'penghalang' yang dapat diaplikasikan di antara kaca penutup dan plat absorber dalam suatu kolektor surya. Penghalang tersebut adalah: a) lembar acrylic $3 \mathrm{~mm}$ yang dipasang di tengah-tengah celah, b) lapisan CA (cellulose acetate) lurus setebal $50 \mu \mathrm{m}$ yang dipasang di tengah-tengah celah, c) lembaran CA yang dibuat bergelombang, d) lembaran CA yang dibuat honeycomb dengan ukuran $9 \mathrm{~mm} \times 9 \mathrm{~mm}$. Dengan penggunaan lembaran CA honeycomb, koefisien kehilangan panas konveksi berkurang sebesar 47\% jika dibandingkan tanpa honeycomb dan berkurang sebesar $18 \%$ jika dibandingkan honeycomb dari acrylic. Ghoneim [5] menemukan bahwa honeycomb dapat mengurangi kehilangan panas dari bagian atas kolektor hingga 52\% tetapi juga mengurangi efisiensi penyerapan radiasi hingga $14 \%$. Pemberian celah di atas dan di bawah honeycomb dapat mengurangi kehilangan panas konveksi, terutama untuk kolektor dengan rentang temperatur yang tinggi dan sedang. Juga ditemukan bahwa celah di bawah (berarti di atas absorber) sangat mempengaruhi koefisien kehilangan panas. Celah dengan ukuran tinggi $3 \mathrm{~mm}$ menghasilkan efisiensi tertinggi. Pada penelitian yang dilakukan Ghoneim [5], lebar celah antara kaca penutup dengan plat absorber datar dijaga konstan, hanya celah di atas dan di bawah yang diubah-ubah.

Dari semua paparan di atas, terlihat bahwa plat absorber bentuk $\mathrm{V}$ dapat meningkatkan koefisien perpindahan panas berguna (useful heat gain) dari plat ke udara dan honeycomb dapat mengurangi kehilangan panas ke sekeliling dari bagian atas kolektor surya. Oleh karena itu perlu dilakukan penelitian untuk menggabungkan plat kolektor bentuk $\mathrm{V}$ dengan honeycomb agar diperoleh performansi kolektor surya yang optimal. Jika Metwally et al. [2] meneliti kolektor dengan kedalaman saluran udara yang berubah-ubah, maka pada penelitian ini akan dilakukan untuk kedalaman saluran udara yang tetap. Sedang Ghoneim [5] meneliti celah di atas dan di bawah honeycomb, pada penelitian ini akan diteliti tinggi honeycomb yang dipakai pada celah antara kaca penutup dan plat yang berbeda-beda.

\section{METODE PENELITIAN}

Penelitian diawali dengan pembuatan suatu kolektor surya udara dengan plat bentuk V. Plat yang digunakan mempunyai sudut puncak $20^{\circ}$, karena Ardiansyah [6] menemukan bahwa sudut puncak $20^{\circ}$ memberikan Quseful dan nilai absorptivitas plat paling tinggi. Kolektor surya yang diuji dapat dilihat pada Gambar 1. Kolektor ini memiliki dimensi: panjang $90 \mathrm{~cm}$, lebar $60 \mathrm{~cm}$ dan kedalaman saluran udara $8,5 \mathrm{~cm}$. Lebar tiap gelombang, $\mathrm{H}$, adalah $3 \mathrm{~cm}$ atau terdapat 20 gelombang $\mathrm{V}$ di mana udara mengalir di dalamnya (seperti pada Gambar 2). Udara lingkungan akan dialirkan masuk ke dalam kolektor dengan bantuan kipas melalui suatu diffuser yang diberi pengarah. Laju aliran udara diatur dengan mengubah kecepatan putaran kipas agar udara mengalir dengan kecepatan 0,$45 ; 0,5$; dan $0,55 \mathrm{~m} / \mathrm{s}$. Data penelitian diambil tiap rentang 15 menit pada pukul 09.00 WIB s/d 15.00 WIB dari tanggal 22 Juli - 3 Agustus 2010. Penelitian dilakukan di Laboratorium Perpindahan Panas dan Massa, Jurusan Teknik Mesin, Institut Teknologi Sepuluh November, Surabaya yang terletak di $7,28^{\circ} \mathrm{LS}$ dan $112,74^{\circ} \mathrm{BT}$.

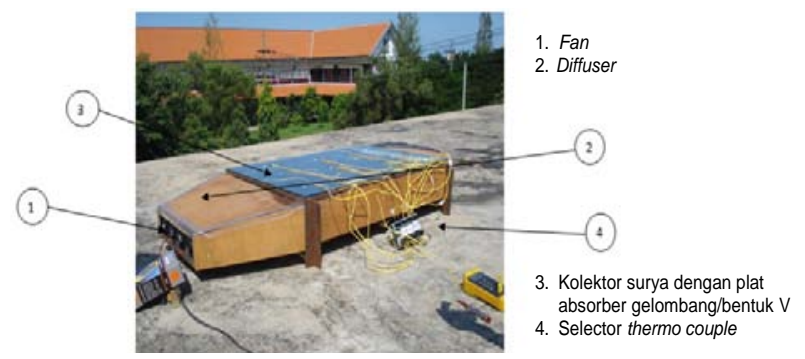

Gambar 1. Kolektor Surya Udara dengan Plat Bentuk V 


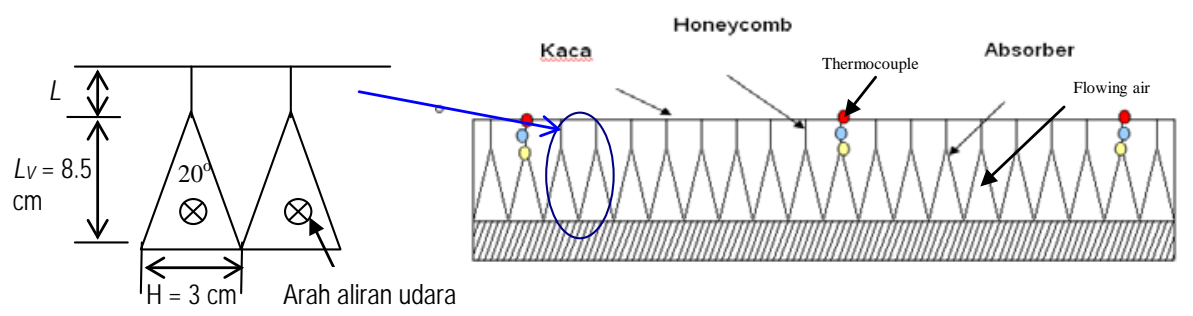

Gambar 2. Skema Kolektor Surya Plat Bentuk V dengan Honeycomb

Tabel 1. Contoh Hasil Pengukuran pada Tanggal 23 Juli 2010 untuk Aspek Rasio, A= 3/1

\begin{tabular}{|c|c|c|c|c|c|c|c|c|c|c|c|c|}
\hline \multirow{2}{*}{ waktu } & \multirow{2}{*}{$\mathrm{V}_{\text {kipas, }} \mathrm{m} / \mathrm{s}$} & \multirow{2}{*}{ I. Radiasi, mV } & \multirow{2}{*}{$\mathrm{V}_{\text {wind }}, \mathbf{m} / \mathbf{s}$} & \multirow{2}{*}{$\mathbf{T}_{\mathbf{a m b}}, \mathbf{C}$} & \multicolumn{3}{|c|}{$\mathbf{T}_{\text {kaca penutup, }} \mathbf{C}$} & \multicolumn{3}{|c|}{$\mathbf{T}_{\text {plat absorber }}, \mathbf{C}$} & \multicolumn{2}{|c|}{$\mathbf{T}_{\text {udara, }} \mathbf{C}$} \\
\hline & & & & & 1 & 2 & 3 & 1 & 2 & 3 & $\mathbf{T}_{\mathrm{f}, \text { in }}$ & $\mathbf{T}_{\text {f, out }}$ \\
\hline \multirow[t]{3}{*}{09.00} & 0,45 & 5,5 & 2,13 & 29 & 45,1 & 48,3 & 47,3 & 54 & 44 & 54,8 & 26,9 & $\overline{42,6}$ \\
\hline & 0,50 & 5,7 & 1,17 & 31 & 48,0 & 52,1 & 52,2 & 58,6 & 48,7 & 59,1 & 26,9 & 46,3 \\
\hline & 0,55 & 5,9 & 3,51 & 30 & 51,6 & 54,7 & 53,9 & 59,5 & 50,7 & 59,7 & 28,3 & 44,2 \\
\hline \multirow[t]{3}{*}{10.00} & 0,45 & 5,8 & 2,55 & 30 & 42,6 & 43,7 & 56,2 & 54,1 & 47,1 & 56,1 & 27 & 39,7 \\
\hline & 0,50 & 5,7 & 3,19 & 32 & 41,9 & 44,2 & 45,4 & 50,9 & 42,6 & 51,1 & 27 & 49,6 \\
\hline & 0,55 & 5,9 & 2,9 & 35 & 42,8 & 44,9 & 46,3 & 44,9 & 40,6 & 47,3 & 30,7 & 43,7 \\
\hline \multirow{4}{*}{$\begin{array}{c}\cdots \\
15.00\end{array}$} & & & & & & & & & & & & \\
\hline & 0,45 & 3,3 & 3,51 & 33 & 40,2 & 41,4 & 42,4 & 45,2 & 45,6 & 47,2 & 32,6 & 42,2 \\
\hline & 0,50 & 2,2 & 1,54 & 32 & 37,6 & 38,5 & 39,5 & 41,7 & 41,5 & 43,5 & 32,2 & 40,2 \\
\hline & 0,55 & 1,9 & 2,12 & 32 & 35,1 & 35,8 & 36,5 & 39,2 & 39,5 & 39,2 & 31 & 33,5 \\
\hline
\end{tabular}

Tabel data untuk pengukuran lainnya dinyatakan pada grafik yang akan dianalisis lebih lanjut.

Gambar skematik kolektor surya udara dengan plat bentuk V ditunjukkan pada Gambar 2. Penelitian dilakukan untuk beberapa aspek rasio yang didesiripisikan sebagai lebar gelombang, dalam hal ini, $H$, dibagi dengan tinggi celah antara puncak plat absorber bentuk $\mathrm{V}$ dengan kaca penutup, dalam hal ini $L$. Dengan demikian, aspek rasio: $A=\frac{H}{L}$. Pada penelitian ini, jarak antara puncak absorber ke kaca penutup yang diberi honeycomb, L, ditentukan sebesar 1, 2, 3, 4, dan $5 \mathrm{~cm}$. Mengingat besar $\mathrm{H}=3$ $\mathrm{cm}$, aspek rasio yang dipakai pada penelitian ini adalah: $\mathrm{A}=3 / 1,3 / 2,3 / 3,3 / 4$, dan $3 / 5$.

Selama pengujian, parameter yang diukur adalah: temperatur udara masuk kedalam saluran $\left(\mathrm{T}_{\text {f,in }}\right)$, temperatur udara keluar saluran $\left(\mathrm{T}_{\mathrm{f}, \mathrm{out}}\right)$, temperatur udara ambient $\left(\mathrm{T}_{\mathrm{amb}}\right)$, temperatur plat absorber $\left(\mathrm{T}_{\mathrm{abs}}\right)$, temperatur kaca penutup $\left(\mathrm{T}_{\mathrm{cg}}\right)$, kecepatan angin $\left(\mathrm{V}_{\mathrm{w}}\right)$, intensitas radiasi $\left(\mathrm{I}_{\mathrm{T}}\right)$ di tempat pengujian, kecepatan udara mengalir dalam saluran (vkipas). Semua pengukuran dicatat seperti dalam Tabel 1.

\section{HASIL DAN PEMBAHASAN}

\section{Pengaruh Aspek Rasio Terhadap Kenaikan Temperatur Udara}

Udara yang mengalir melalui kolektor surya mengalami pemanasan sehingga temperaturnya meningkat dari $\mathrm{T}_{\mathrm{f} \text {,in }}$ menjadi $\mathrm{T}_{\mathrm{f}, \text { out }}$. Penggunaan honeycomb dengan berbagai aspek rasio mempengaruhi kenaikan temperatur yang dialami udara, seperti terlihat pada Gambar 3a sampai 5a untuk masing-masing kecepatan udara 0,45; 0,5; dan 0,55 $\mathrm{m} / \mathrm{s}$. Kenaikan temperatur udara juga sangat dipengaruhi intensitas radiasi matahari yang diterima plat absorber pada saat pengukuran. Data intensitas matahari saat pengukuran dapat dilihat pada Gambar 3b sampai 5b.

Dari Gambar 3 sampai 5, terlihat bahwa pada semua kecepatan dan aspek rasio yang diuji, udara yang mengalir melalui kolektor surya mengalami kenaikan temperatur dan kenaikan temperatur tertinggi terjadi ketika aspek rasio yang digunakan adalah 3/1. Namun, mulai pukul 13.00 kenaikan temperatur menurun untuk semua kecepatan udara dan aspek rasio. Hal ini karena intensitas radiasi yang diterima mengecil. Udara dapat mengalami kenaikan temperatur hingga $22^{\circ} \mathrm{C}$ untuk aspek rasio $3 / 1$ dan kecepatan udara $0,5 \mathrm{~m} / \mathrm{s}$ pada pukul10.00. Kenyataan ini sesuai dengan hasil yang didapat Ghoneim [4] yaitu bahwa untuk daerah kerja dengan rentang temperatur tidak terlalu tinggi, penggunaan honeycomb yang pendek dapat mengurangi rugi-rugi panas konveksi dan memberikan transmisi-absorpsi optik $(\tau \alpha)$ lebih baik dibanding honeycomb yang tinggi. Dengan kata lain penggunaan honeycomb yang tinggi menyebabkan rugirugi panas konveksi lebih besar dan transmisiabsorpsi optik $(\tau \alpha)$ lebih kecil bila dibanding dengan honeycomb yang pendek. 


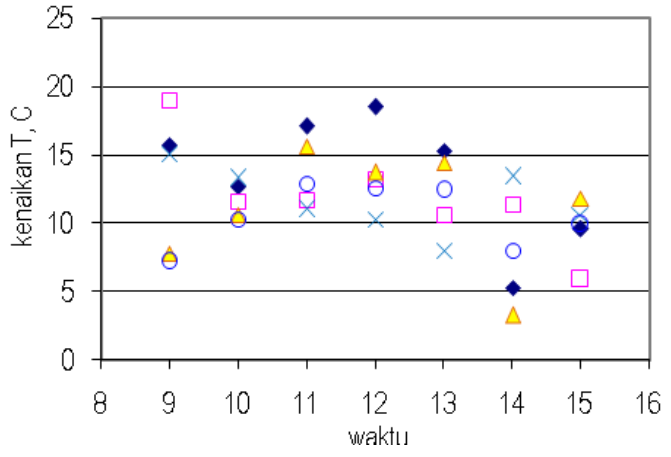

(a) Kenaikan Temperatur

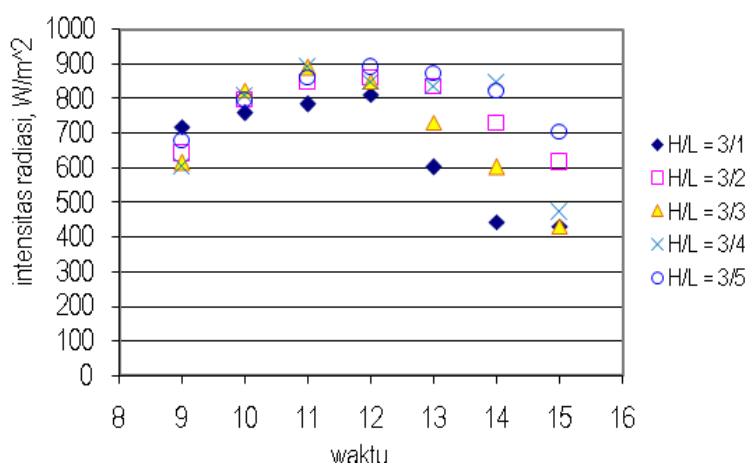

(b) Intensitas Radiasi

Gambar 3. Perubahan Temperatur dan Intensitas Radiasi Matahari pada Kecepatan Udara 0,45 m/s

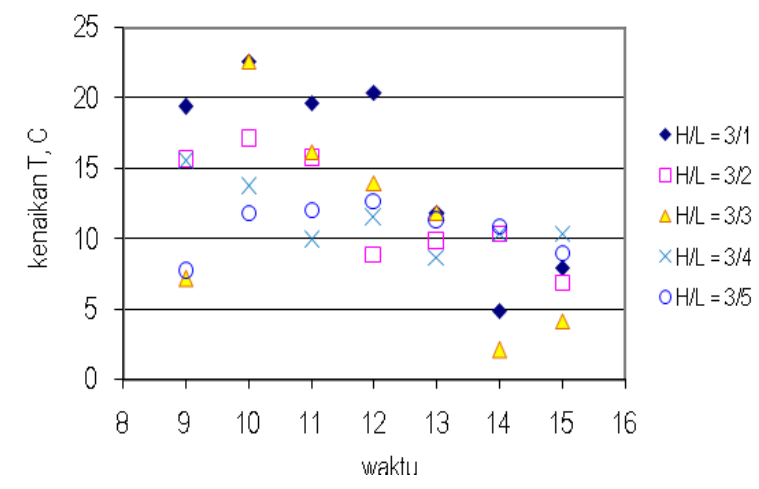

(a) Perubahan Temperatur selama waktu Penelitian

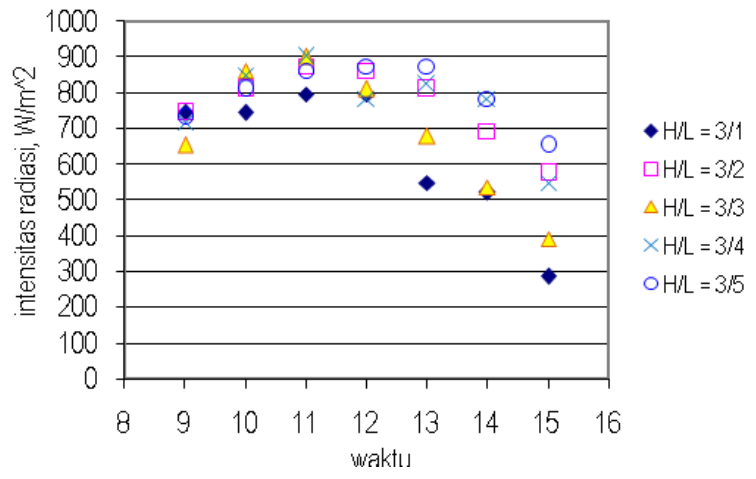

(b) Perubahan Intensitas Radiasi selama waktu Penelitian

Gambar 4. Kenaikan Temperatur dan Intensitas Radiasi Matahari pada Kecepatan Udara 0,5 m/s

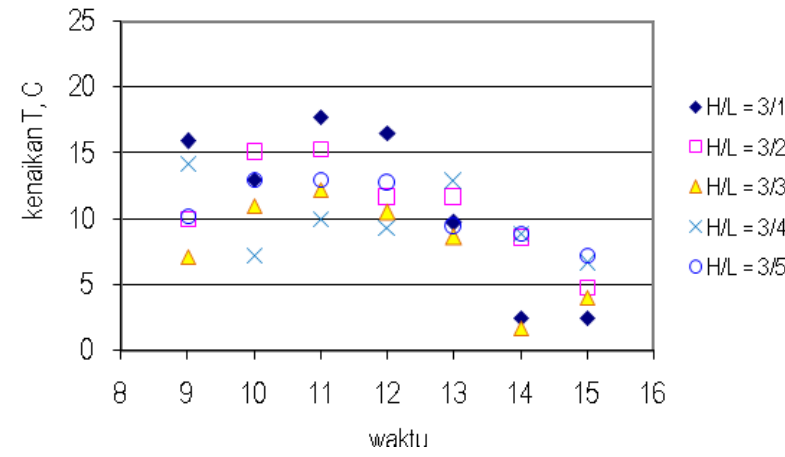

(a) Kenaikan Temperatur

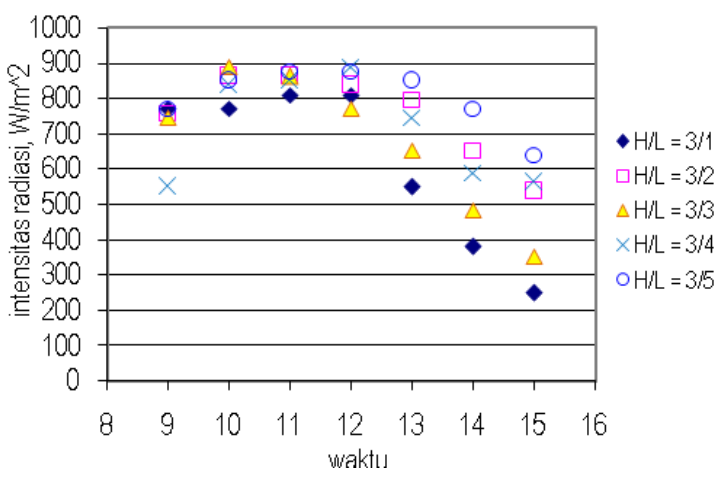

(b) Intensitas Radiasi

Gambar 5. Kenaikan Temperatur dan Intensitas Radiasi Matahari pada Kecepatan Udara 0,55 m/s

Kenaikan temperatur pada saat udara mengalir dengan kecepatan $0,5 \mathrm{~m} / \mathrm{s}$ adalah yang paling tinggi dari tiga kecepatan yang diuji, seperti pada Gambar 3 sampai 5. Fluida yang mengalir dengan kecepatan lebih tinggi akan lebih turbulen karena fluida memiliki bilangan Reynolds dan bilangan Nusselt lebih tinggi, sehingga koefisien konveksi antara permukaan plat absorber dengan aliran udara di bawahnya juga akan lebih tinggi. Kenaikan koefisien konveksi berarti perpindahan panas dari plat absorber ke udara menjadi lebih besar, sehingga udara mengalami kenaikan temperatur lebih tinggi dari udara dengan kecepatan lebih rendah, yaitu $0,45 \mathrm{~m} / \mathrm{s}$.

Namun, kenaikan kecepatan aliran udara dalam saluran membuat rugi panas yang hilang ke lingkungan ikut meningkat seperti ditunjukkan oleh koefisien rugi panas, $U$, pada Tabel 2 . Koefisien rugi panas ' $U$ ' ditentukan dari rugi panas yang hilang dari plat absorber ke udara diam di atas plat di antara honeycomb, ke kaca penutup, dan akhirnya ke udara atau angin yang bertiup di luar kaca penutup kolektor. Pada semua aspek rasio yang diuji, koefisien rugi panas meningkat dengan kenaikan kecepatan aliran udara. Dari Persamaan 1 terlihat bahwa kenaikan koefisien rugi panas yang hilang, $U$, menyebabkan penurunan $Q_{\text {useful }}$ yang kemudian menyebabkan penurunan kenaikan temperatur udara, $T_{f, \text { out }}-T_{f, i n}$. 
Tabel 2. Koefisien Rugi Panas (Wm².K), Plat Absorber ke Udara Sekitar

\begin{tabular}{lllllllll}
\hline & $\mathbf{j a m}$ & $\mathbf{9}$ & $\mathbf{1 0}$ & $\mathbf{1 1}$ & $\mathbf{1 2}$ & $\mathbf{1 3}$ & $\mathbf{1 4}$ & $\mathbf{1 5}$ \\
\hline $\mathbf{A}=3 / \mathbf{1}$ & $\mathrm{V}=0,45 \mathrm{~m} / \mathrm{s}$ & 4,132 & 4,164 & 4,170 & 4,164 & 4,207 & 4,202 & 4,192 \\
& $\mathrm{~V}=0,5 \mathrm{~m} / \mathrm{s}$ & 4,282 & 4,311 & 4,298 & 4,331 & 4,310 & 4,297 & 4,331 \\
& $\mathrm{~V}=0,55 \mathrm{~m} / \mathrm{s}$ & 4,452 & 4,430 & 4,453 & 4,470 & 4,491 & 4,485 & 4,472 \\
$\mathbf{A}=3 / \mathbf{2}$ & $\mathrm{V}=0,45 \mathrm{~m} / \mathrm{s}$ & 4,132 & 4,169 & 4,170 & 4,184 & 4,234 & 4,202 & 4,191 \\
& $\mathrm{~V}=0,5 \mathrm{~m} / \mathrm{s}$ & 4,325 & 4,315 & 4,372 & 4,345 & 4,344 & 4,350 & 4,344 \\
& $\mathrm{~V}=0,55 \mathrm{~m} / \mathrm{s}$ & 4,416 & 4,420 & 4,485 & 4,496 & 4,534 & 4,505 & 4,466 \\
$\mathbf{A}=3 / \mathbf{3}$ & $\mathrm{V}=0,45 \mathrm{~m} / \mathrm{s}$ & 4,141 & 4,170 & 4,172 & 4,178 & 4,227 & 4,205 & 4,198 \\
& $\mathrm{~V}=0,5 \mathrm{~m} / \mathrm{s}$ & 4,273 & 4,272 & 4,381 & 4,355 & 4,343 & 4,352 & 4,341 \\
& $\mathrm{~V}=0,55 \mathrm{~m} / \mathrm{s}$ & 4,386 & 4,417 & 4,493 & 4,514 & 4,541 & 4,522 & 4,498 \\
$\mathbf{A}=3 / \mathbf{4}$ & $\mathrm{V}=0,45 \mathrm{~m} / \mathrm{s}$ & 4,147 & 4,172 & 4,191 & 4,191 & 4,229 & 4,215 & 4,201 \\
& $\mathrm{~V}=0,5 \mathrm{~m} / \mathrm{s}$ & 4,279 & 4,282 & 4,394 & 4,432 & 4,363 & 4,346 & 4,341 \\
& $\mathrm{~V}=0,55 \mathrm{~m} / \mathrm{s}$ & 4,398 & 4,428 & 4,497 & 4,509 & 4,553 & 4,534 & 4,498 \\
$\mathbf{A}=3 / \mathbf{5}$ & $\mathrm{V}=0,45 \mathrm{~m} / \mathrm{s}$ & 4,152 & 4,181 & 4,204 & 4,222 & 4,240 & 4,207 & 4,200 \\
& $\mathrm{~V}=0,5 \mathrm{~m} / \mathrm{s}$ & 4,249 & 4,301 & 4,403 & 4,430 & 4,414 & 4,376 & 4,336 \\
& $\mathrm{~V}=0,55 \mathrm{~m} / \mathrm{s}$ & 4,359 & 4,434 & 4,540 & 4,547 & 4,542 & 4,530 & 4,514 \\
\hline
\end{tabular}

$$
\dot{\mathrm{Q}}_{\text {useful }}=\dot{\mathrm{mc}} \mathrm{p}\left(\mathrm{T}_{\mathrm{f}, \text { out }}-\mathrm{T}_{\mathrm{f}, \text { in }}\right)=\mathrm{A}_{\mathrm{c}}\left(\mathrm{S}-\mathrm{U}\left(\mathrm{T}_{\text {absorber }}-\mathrm{T}_{\mathrm{amb}}\right)\right)
$$

Persamaan 1 menyebabkan kenaikan temperatur udara pada saat udara mengalir dengan kecepatan $0.55 \mathrm{~m} / \mathrm{s}$ lebih rendah dari $0.5 \mathrm{~m} / \mathrm{s}$.

\section{Pengaruh Aspek Rasio pada Efisiensi Kolektor}

Menurut Duffie [7], efisiensi kolektor dideskripsikan sebagai perbandingan antara panas yang diterima udara yang mengalir terhadap intensitas radiasi matahari di tempat pengujian seperti pada Persamaan 2.

$$
(\mathrm{n})_{\text {act }}=\frac{\mathrm{Q}_{\mathrm{U}}}{\mathrm{I}_{\mathrm{T}} \cdot \mathrm{A}_{\mathrm{C}}}=\frac{\dot{\mathrm{m}} \mathrm{c}_{\mathrm{p}}\left(\mathrm{T}_{\mathrm{f} \text { out }}-\mathrm{T}_{\mathrm{f}, \mathrm{in}}\right)}{\mathrm{I}_{\mathrm{T}} \mathrm{A}_{\mathrm{c}}}
$$

Dengan menggunakan Persamaan 2, maka kinerja kolektor, yaitu efisiensi, pada berbagai aspek rasio dapat dianalisa meskipun intensitas radiasi matahari berubah-ubah. Dari hasil penelitian, seperti pada Gambar 6a hingga 6c, terlihat bahwa kolektor mempunyai efisiensi terbaik saat aspek rasio, $\mathrm{A}=3 / 1$. Efisiensi sesaat (instanteneous efficiency) kolektor dengan aspek rasio, $\mathrm{A}=3 / 1$ dapat mencapai $47 \%$ pada pk. 10.00. Efisiensi kolektor berkurang dengan pertambahan aspek rasio. Efisiensi paling rendah didapat ketika aspek rasio, A $=3 / 5$. Semakin besar aspek rasio berarti honeycomb yang dipakai semakin tinggi. Hal ini membuat radiasi matahari yang diserap absorber lebih rendah, sehingga temperatur plat absorber dan efisiensi kolektor menjadi lebih rendah.

Efisiensi kolektor surya dapat dinyatakan sebagai fungsi $\frac{\left(\mathrm{T}_{\text {absorber }}-\mathrm{T}_{\text {ambient }}\right)}{\mathrm{I}_{\mathrm{T}}}$ seperti terlihat pada Gambar 7 untuk aspek rasio, $\mathrm{A}=3 / 1$. Efisiensi kolektor paling tinggi saat kecepatan udara dalam saluran $0,5 \mathrm{~m} / \mathrm{s}$. Data pada Gambar 7 terlihat menyebar di atas dan di bawah garis, karena harga koefisien rugi panas, $U$, tidak konstan. Hal ini bersesuaian dengan yang disampaikan Duffie [7].

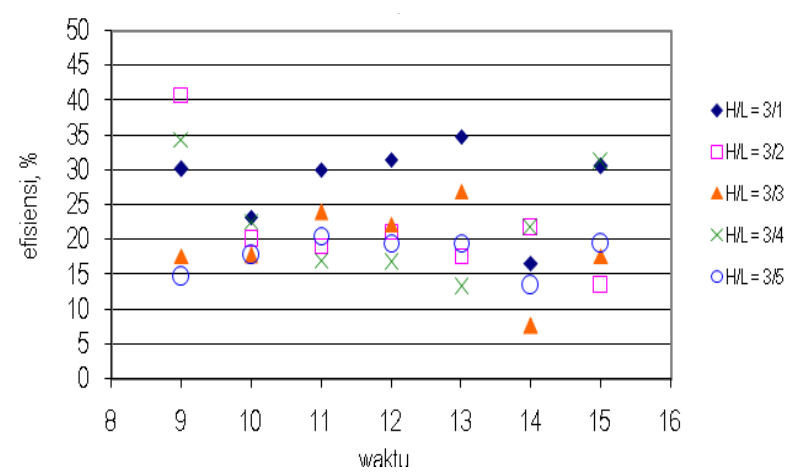

(a) Kecepatan Udara $0,45 \mathrm{~m} / \mathrm{s}$

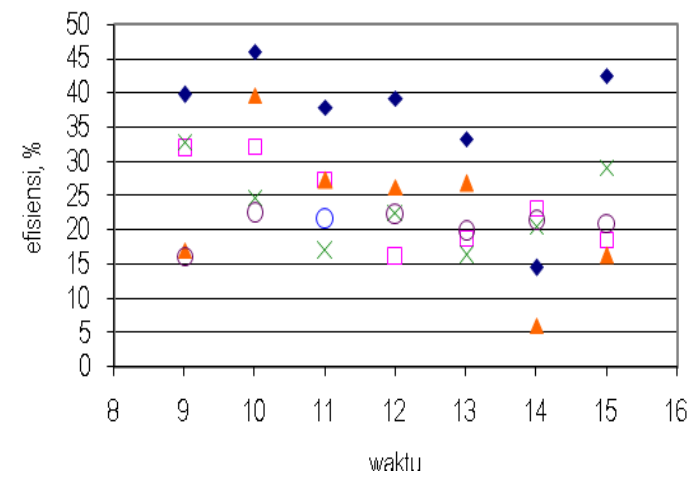

- HIL $=3 / 1$ $\square \mathrm{HL}=32$ $\triangle H L=3 B$ $\mathrm{XHIL}=3.4$ $\mathrm{OHIL}=35$

(b) Kecepatan Udara 0,5 m/s

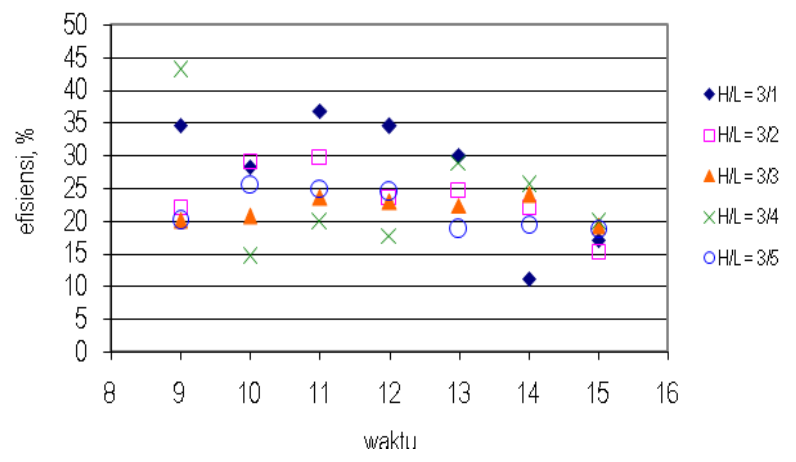

(c) Kecepatan Udara 0,55 m/s

Gambar 6. Efisiensi Kolektor Surya Fungsi Kecepatan Udara 


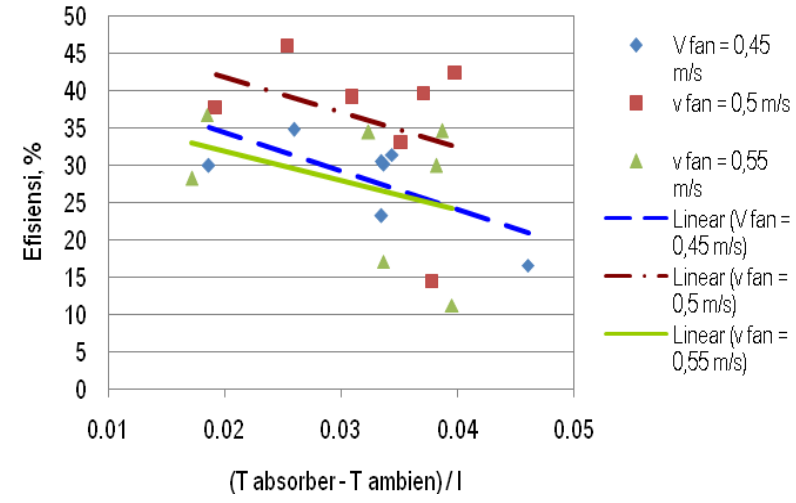

Gambar 7. Efisiensi Kolektor Surya pada Aspek Rasio, $\mathrm{A}=3 / 1$

Efisiensi kolektor surya dapat dinyatakan sebagai fungsi $\frac{\left(\mathrm{T}_{\text {absorber }}-\mathrm{T}_{\text {ambient }}\right)}{\mathrm{I}_{\mathrm{T}}}$ seperti terlihat pada Gambar 7 untuk aspek rasio, $A=3 / 1$. Efisiensi kolektor paling tinggi saat kecepatan udara dalam saluran $0,5 \mathrm{~m} / \mathrm{s}$. Data pada Gambar 7 terlihat menyebar di atas dan di bawah garis, karena harga koefisien rugi panas, $U$, tidak konstan. Hal ini bersesuaian dengan yang disampaikan Duffie [7].

\section{KESIMPULAN}

Dari pengujian yang dilakukan, dapat disimpulkan bahwa kolektor surya dengan plat absorber bentuk $\mathrm{V}$ yang dilengkapi honeycomb mempunyai unjuk kerja terbaik saat udara mengalir melalui saluran berbentuk $\mathrm{V}$ dengan kecepatan $0,5 \mathrm{~m} / \mathrm{s}$ dengan aspek rasio antara lebar $\mathrm{V}$ dengan tinggi honeycomb sebesar 3/1. Unjuk kerja yang dimaksud adalah kenaikan temperatur aliran udara dan efisiensi kolektor.

\section{DAFTAR PUSTAKA}

1. C. Choudhury and H. P. Garg. Design Analiysis of Corrugated and Flat Plate Solar Air Heaters. Renewable Energy Vol I, No. 5/6, p. 595 - 607, 1991.

2. M. N. Metwally, H. Z. Abou-Ziyan, and A. M. ElLeathy. Performance of Advanced CorrugatedDuct Solar Air Collector Compared with Five Conventional Designs. Renewable Energy, Vol. 10, No. 4, p. 519 - 537, 1997.

3. Md Azharul Karim and M. N. A Hawlader, Performance Investigation of Flat Plate, VCorrugated and Finned Air Collector, Energy 31, p. 452-470, 2004.

4. H. Suehrcke, D. Däldehög, J. A. Harris, R. W. Lowe. Heat Transfer Across Corrugated Sheets and Honeycomb Transparent Insulation. Solar Energy 76, p. $351-358,2004$.

5. A. A. Ghoneim, Performance Optimization of Solar Collector Equipped with Different Arrangements of Square-Celled Honeycomb, International Journal Of Thermal Sciences 44, p. 95 - 105, 2005.

6. Reza Ardiansyah, Studi Eksperimental Performansi Kolektor Surya Absorber Gelombang Tipe$V$, Tugas Akhir - TM 091486, Institut Teknologi Sepuluh Nopember, 2010.

7. John A. Duffie, Solar Engineering of Termal Processes, $2^{\text {nd }}$ ed., John Wiley \& Sons, Inc., 1991. 